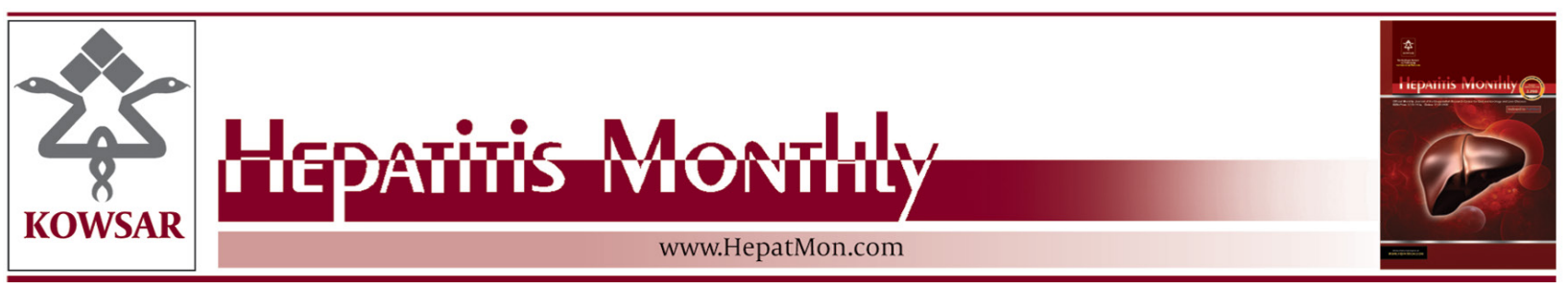

\title{
A Survey of Correlation Between Insulin-Like Growth Factor-I (IGF-I) Levels and Severity of Liver Cirrhosis
}

\author{
Asghar Khoshnood ${ }^{1,}$, , Mohsen Nasiri Toosi ${ }^{2}$, Mohammad Jafar Faravash ${ }^{2}$, Alireza Es- \\ teghamati ${ }^{3}$, Hosein Froutan ${ }^{2}$, Hadi Ghofrani ${ }^{2}$, Mohammad Kalani ${ }^{2}$, Arash Miroliaee ${ }^{2}$, \\ Ahmad Abdollahi ${ }^{4}$, Andrabi Yasir ${ }^{2}$ \\ ${ }^{1}$ Department of Internal Medicine, Shahid Sadoughi Hospital, Shahid Sadoughi University of Medical Sciences, Yazd, IR Iran \\ 2 Department of Gastroenterology, Imam Khomeini Hospital, Tehran University of Medical Sciences, Tehran, IR Iran \\ ${ }^{3}$ Department of Endocrinology, Imam Khomeini Hospital, Tehran University of Medical Sciences, Tehran, IR Iran \\ ${ }^{4}$ Department of Pathology, Imam Khomeini Hospital, Tehran University of Medical Sciences, Tehran, IR Iran \\ * Corresponding author: Asghar Khoshnood, Department of Internal Medicine, Shahid Sadoughi Hospital, Shahid Sadoughi University of Medical Sciences, \\ Yazd, IR Iran. Tel.: +98-3518224000, Fax: +98-3518224100, E-mail: Askhoshnood@yahoo.com.
}

\begin{abstract}
A B S T R A C T
Background: Insulin-like growth factor is a polypeptide with endocrine, autocrine and paracrine effects which its structure is similar to the insulin molecule. While various tissues secrete IGF-1, 90\% of the circulating IGF-1 is secreted by liver.Cirrhosis of liver is a condition accompanied by decreased level of IGF-1, in which the level of IGF-1 may be further decreased thorough the progression of the disease.

Objectives: The aim of the present study was to demonstrate the relation between the IGF-1 levels and severity of liver disease according to Child-Pugh and Model for end stage liver diseases (MELD) Scores.

Patients and Method:This was a descriptive-analytic cross sectional study performed on patients with cirrhosis admitted togastroenterology clinic of Imam Khomeini Hospital in Tehran, Iran during the years 2007-2008. The diagnosis was based on liver biopsy. Initially for all patients, laboratory investigations including IGF-1, CBC, liver Enzymes, Alkaline phosphates, serum Albumin, Creatinine, direct and total Bilirubin were conducted. Also ultrasound and endoscopy were performed for evaluation of ascites and varices.

Results: 100 patients with cirrhosis with a male to Female ratio of 63:37 and a mean age of $44.4 \pm 15$ years were enrolled in the study. Median IGF-1 was $92.95 \pm 91.51 \mathrm{ng} / \mathrm{mL} .14$ patients (14\%) had IGF-1 within normal limits while 86 patients ( $86 \%$ ) had abnormal IGF-1 levels. In all patients the correlation coefficient between IGF-1 and MELD was -0.317 ( $\mathrm{P}=0.001)$ and 0.478 between IGF-1 and Child-Pugh $(\mathrm{P}<0.001)$.

Conclusions: Our findings showed that IGF-1 can be used as an index for evaluating the severity of cirrhosis; also it can be used for determining the severity of the disease, when liver biopsy is not possible.
\end{abstract}

Keywords: Insulin-Like Growth Factor I; Liver Cirrhosis; Child

Copyright ( 2013, Kowsar Corp.; Published by Kowsar Corp.

Article type: Research Article; Received: 09 May 2012, Revised: 13 Jun 2012, Accepted: 28 Jul 2012; DOI: 10.5812/hepatmon.6181

Implication for health policy/practice/research/medical education:

The results of this study give an alternative choice to physicians for better interpretation on severity of diseases in patients with liver cirrhosis especially when liver biopsy is impossible. Also this study can be interesting for researchers to use results of this study in future studies possibly to organize a new criteria on severity and prognosis of liver cirrhosis.

Please cite this paper as:

Khoshnood A, Nasiri Toosi M, Faravash MJ, Esteghamati A, Froutan H, Ghofrani H, et al. A Survey of Correlation Between Insulin-Like Growth Factor-I (IGF-I) Levels and Severity of Liver Cirrhosis. Hepat Mon. 2013;13(2):e6181. DOI: 10.5812/hepatmon.6181

Copyright (C2013, Kowsar Corp;; Published by Kowsar Corp.

This is an Open Access article distributed under the terms of the Creative Commons Attribution License (http://creativecommons.org/licenses/by/3.0), which permits unrestricted use, distribution, and reproduction in any medium, provided the original work is properly cited. 


\section{Background}

Insulin like growth factor-1 (IGF-1) is a polypeptide with endocrine autocrine, paracrine effect which has some structural similarities with the insulin molecule (1). IGF1 levels can be measured in the blood in 10-1000 $\mathrm{ng} / \mathrm{ml}$ amounts. As levels do not fluctuate greatly throughout the day for an individual person, IGF-1 is used by physicians as a screening test for growth hormone deficiency and its excess in acromegaly and gigantism. Normal range values of IGF-1 have been determined in detail for specific age groups. Because of the wide range of hormone value, normal ranges have been reported by percentiles for each age group $(2,3)$. While various tissues secretes IGF-1, $90 \%$ of the circulating IGF-1 is secreted by liver (4). The release of IGF-1 from liver is stimulated by the growth hormone (5). Hepatocytes contain GH receptors; in which stimulation of these receptors increases the production and secretion of IGF-1 from the hepatocytes into plasma (6). IGF-1 is an anabolic hormone which causes a decrease in proteolysis and an increased stimulation of protein production, followed by an increase in muscular mass $(7,8)$. Liver cirrhosis is a state accompanied by a decrease in IGF-1 and progression of the disease (9-13). In liver cirrhosis IGF-1 level would be decreased while growth hormone would be increased (14). This decrease in IGF-1 is because of two factors; firstly, the decrease in growth hormone receptors in patients with cirrhosis and secondly progressive reduction in production of IGF-1 that is due to a decrease in hepatocytes (15-17). Increase in growth hormone is due to loss of inhibitory effect of IGF-1 on the hypothalamus or the hypophysis. Unresponsive- ness of hepatocytes to growth hormone in child $\mathrm{C}$ will be determined by minimum rise of IGF-1 level ( $<10 \%)$ in response to the growth hormone compared to more than $20 \%$ rise in normal population (9). Some nutritional and metabolic factors are effective on decreased levels of IGF1. In fact, patients with cirrhosis have malnutrition like state, which is similar to patients undergoing prolonged fasting i.e. increased gluconeogenesis from liver and muscles (18-20). Child-Pugh scoring system is a suitable clinical method to determine the severity of disease in liver cirrhosis, and also involves qualitative criteria such as encephalopathy and ascites in addition to quantitative criteria, therefore can be used for staging (21) (Table 1). Child-Pugh class will be categorized in three classes, class A (a score of 5-6, one year's survival of $100 \%$ and two years survival of $85 \%$ ), Class B (7-9, one year's survival of $81 \%$ and two years survival of $57 \%$ ), Class C (10 or above, one year's survival of $45 \%$ and two years survival of $35 \%)$. Similarly the Model for End stage liver disease (MELD) scoring system is a method in which qualitative criteria (Bilirubin, creatinine and INR) used to determine the severity of liver involvement. Score will be calculated by the following formula (22): MELD = $0.957 \times$ loge [creatinine $(\mathrm{mg} / \mathrm{dL})]+$ $0.378 \times$ loge $[\operatorname{Bil}(\mathrm{mg} / \mathrm{dL})]+1.12 \times$ loge $($ INR $)+0.643$. In interpreting the MELD Score in hospitalized patients, the 3 month mortality is (23):

40 or more $-71.3 \%$ mortality

30-39-52.6\% mortality

20-29-19.6\% mortality

$10-19-6.0 \%$ mortality

$<9-1.9 \%$ mortality

Table 1. Child-Pugh Classification of Cirrhosisa

\begin{tabular}{llll}
\hline & \multicolumn{3}{c}{ Classification of Cirrhosis } \\
\cline { 2 - 4 } & A & B & C \\
\hline Albumin & $>3.5 \mathrm{~g} / \mathrm{dL}$ & $3-3.5 \mathrm{~g} / \mathrm{dL}$ & $<3 \mathrm{~g} / \mathrm{dL}$ \\
Bilirubin & $<2 \mathrm{mg} / \mathrm{dL}$ & $2-3 \mathrm{mg} / \mathrm{dL}$ & $>3 \mathrm{mg} / \mathrm{dL}$ \\
Protrombin time & $<15 \mathrm{sec}$ & $15-17 \mathrm{sec}$ & $>17 \mathrm{sec}$ \\
\hline Ascites & without ascites & mild to moderate ascites & severe ascites \\
Encephalopathy & without encephalopathy & mild encephalopathy & advanced encephalopathy \\
\hline${ }^{\text {a }}$ Child-Pugh class A (a score of 5-6, one year's survival of 100\% and two years survival of 85\% ), Class B (7-9, one year's survival of $81 \%$ and two years \\
survival of 57\%), Class C (10 or above, one year's survival of 45\% and two years survival of 35\%)
\end{tabular}

\section{Objectives}

There are few studies on the role of IGF 1 as an index for determining the severity of the disease in patients with cirrhosis. Also detecting the relationship among IGF 1 and MELD and child-pugh criteria's is missed in existing studies. Therefore in this study, we decided to find the relation between IGF-1 and severity of liver disease according to the MELD and child-pugh criteria.

\section{Patients and Methods}

This descriptive-analytic cross sectional study was performed on patients with cirrhosis which were admitted to the gastroenterology clinic at Imam Khomeini Hospital, Tehran, Iran, during the years 2007-2008. The diagnosis was based on liver biopsy or clinical criteria. Exclusion criteria included advanced encephalopathy, Hepatorenal syndrome, recent infections, diabetes, chronic renal dis- 
eases, gastro-intestinal bleeding and past history of malignancy. In view of the study conducted by Vyzartiadis (24) where IGF-1 mean levels was calculated as $28.9 \pm 3$ in patients with cirrhosis, a sample size of at least 82 patients with an accuracy of $6.5 \%$ and a confidence limit of $95 \%$ was needed for our study. Initially the lab studies including AST, ALT, Alkaline phosphatase, Platelets, C.B.C, serum creatinine, serum albumin and Direct and total bilirubin were measured for all patients. Similarly ultrasound for the detection of ascites and endoscopy for varices were performed. Then severity of liver disease was determined according to Child-Pugh criteria (Table 1) and MELD score. The MELD score was calculated by the free software available on Mayo clinic website (http/www.mayoclinic.org/ gi-rst/mayomode/5.html), which was based on the formula previously mentioned in introduction. Thereafter, IGF-1 measurement was performed using bio source kits, radioimmunoassay and protein binding methods. For this purpose specific amount of labeled IGF-1 and Iodine 125 (I 125) with the sample for which IGF-1 level had to be determined were placed in polyester test tubes. After two hours of centrifugation at room temperature and incubatory condition, the sediment was collected, and then IGF-1 concentration was determined by negative calibration. All the collected data was analyzed using SPSS-16. P value below 0.05 was considered as significant.

\section{Results}

This study was conducted on 100 liver cirrhosis patients. 63 patients (63\%) were male and 37 (37\%) were female. The mean age of patients was $44.4 \pm 15$ years with the range of 12 to74 years. Table 2 shows the frequency of etiologic factors of liver cirrhosis. Based on clinical information which was registered from patients `documents, 66 patients (66\%) had esophageal varices, 82 (82\%) had ascites (66 patients (66\%) moderate ascites and 16 patients (16\%) severe ascites) and 87 patients (87\%) had splenomegaly. Mean IGF level was 92.95 \pm 91.51. IGF-1 level in 14 patients
(14\%) was within the normal range while 86 patients (86\%) had abnormal IGF-1 values. Table 3 indicates the ratio and the frequency of Child-Pugh classes according to the IGF state. The mean values for IGF- 1 was $167.43 \pm 121 \mathrm{ng} / \mathrm{mL}$ for class A, $64.65 \pm 45.13$ for class B and $57.61 \pm 52.9$ for class C patients where the difference was significant among the groups ( $\mathrm{P}<0.001$, ANOVA). Our study findings showed that MELD index mean value was $15 \pm 5.3$ in patients and correlation coefficient was -0.317 ( $\mathrm{P}=0.001$, ANOVA) between IGF-1 and MELD index (Figure 1). Also correlation coefficient between IGF-1 and Child-Pugh score was -0.478 $(\mathrm{P}<0.001)$ (Figure 2). Table 4 shows correlation coefficient among Child-Pugh score, MELD and IGF-1 according to sex. For further assessment of relation among IGF-1 and Child-Pugh and MELD indices, mean of MELD and ChildPugh indices were calculated according to normal and abnormal values of IGF-1. Mean Child-Pugh score in patients with normal IGF-1 value was $5.5 \pm 5.2$ compared to $8.7 \pm 2.2$ in patients with abnormal IGF-1 values $(\mathrm{P}<0.001)$. Similarly mean MELD score in patients who had normal and abnormal IGF-1 levels was $11 \pm 4.5$ and $15.7 \pm 5.2$ respectively, which shows a significant difference $(P=0.002)$. Also correlation coefficient between IGF and age was determined as $0.445(\mathrm{P}<0.001)$. There were no significant relation between gender and abnormal IGF-1 since $35.7 \%$ (five patients) female and $64.3 \%$ (nine patients) male had normal IGF-1 values while $27.3 \%$ (32 patients) of female and $62.8 \%$ (54 patients) of male patients had abnormal IGF-1 levels $(\mathrm{P}=0.0914)$. Also there were no statistically significant difference between esophageal varices and IGF-1, as $64.3 \%$ of patients with normal IGF-1 values had esophageal varices compared to $66.3 \%$ of patients who had abnormal IGF-1 ( $\mathrm{P}=0.884$ ) values. However, significant relation between IGF-1 level and splenomegaly was found since $35.7 \%$ of patients with normal IGF-1 values had splenomegaly compared to $95.3 \%$ of patients with abnormal IGF-1 ( $\mathrm{P}<0.001)$ levels. Table 5 shows correlation between IGF-1 and lab indices.

Table 2. Frequency of Etiologic Factors in the Development of Cirrhosis in PatientsUnder Study

\begin{tabular}{ll}
\hline Frequency Etiology & Patients, No. (\%) \\
\hline Hepatitis B & $25(25)$ \\
\hline Autoimmune hepatitis & $25(25)$ \\
\hline Hepatitis C & $22(22)$ \\
Cryptogenic & $17(17)$ \\
\hline Primary Sclerosing Cholangitis & $5(5)$ \\
Budd-Chiari Syndrome & $4(4)$ \\
Wilson & $2(2)$ \\
\hline Total & 100 \\
\hline
\end{tabular}


Table 3. Ratio and Frequency of Child-Pugh Classes According to the IGF-1 Level

\begin{tabular}{|c|c|c|c|}
\hline IGF-1 Child Class & Normal IGF-1 value, No. (\%) & $\begin{array}{l}\text { Abnormal IGF-1 value, No. } \\
(\%)^{a}\end{array}$ & Total, No. (\%) \\
\hline A & $13(13)$ & $17(17)$ & $30(100)$ \\
\hline B & $0(0)$ & $34(34)$ & $34(100)$ \\
\hline C & $1(1)$ & $36(36)$ & $36(100)$ \\
\hline Total & $14(14)$ & $86(86)$ & $100(100)$ \\
\hline
\end{tabular}

Abbreviation: IGF-1, insulin-like growth factor-1

${ }^{\text {a }}$ Normal:(90-360)

Table 4. Correlation CoefficientBetween Study Indices According to Gender (ANOVA)

\begin{tabular}{llll}
\hline Index & \multicolumn{2}{c}{ Correlation Co-Efficient } & Pvalue \\
\hline & & Male $(\mathbf{n}=\mathbf{6 3})$ & \\
\hline IGF-1 - Child-Pugh score & 0.412 & & 0.001 \\
\hline IGF-1 - MELD & 0.307 & & 0.014 \\
& & Female $(\mathbf{n}=37)$ & 0.001 \\
\hline IGF-1 - Child-Pugh score & 0.622 & & 0.011 \\
\hline IGF-1 - MELD & 0.4157 & & \\
\hline
\end{tabular}

Abbreviation: IGF-1, insulin-like growth factor-1

Table 5. CorrelationBetween IGF-1 and Study Lab Indices (ANOVA)

\begin{tabular}{lll}
\hline Indices & Correlation Co-Efficient & Pvalue \\
\hline IGF-1-bilirubin & -0.188 & 0.061 \\
\hline IGF-1-INR & -0.261 & 0.009 \\
\hline IGF-1-platelets & 0.361 & 0.001 \\
\hline IGF-1-creatinine & -0.278 & 0.005 \\
\hline IGF-1-albumin & 0.645 & 0.001 \\
\hline
\end{tabular}

Abbreviation: IGF-1, insulin-like growth factor-1

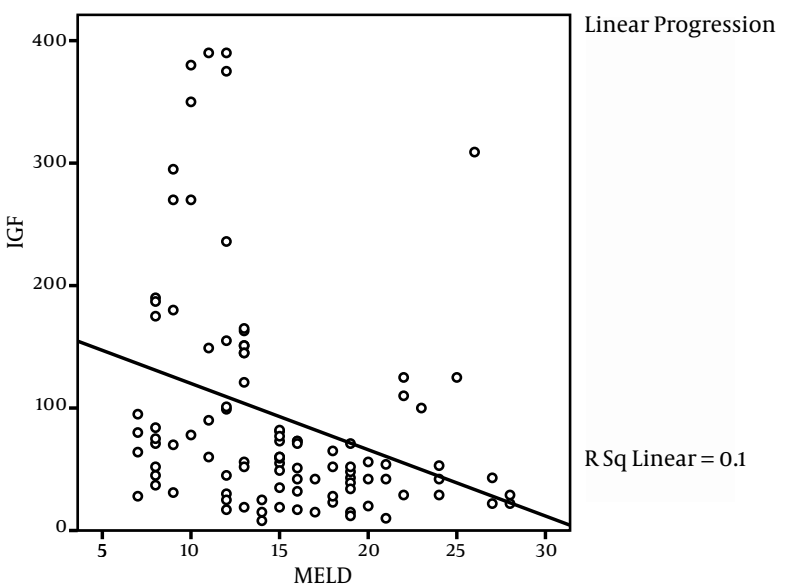

Figure 1. Linear Correlation Between MELD Score and IGF-1

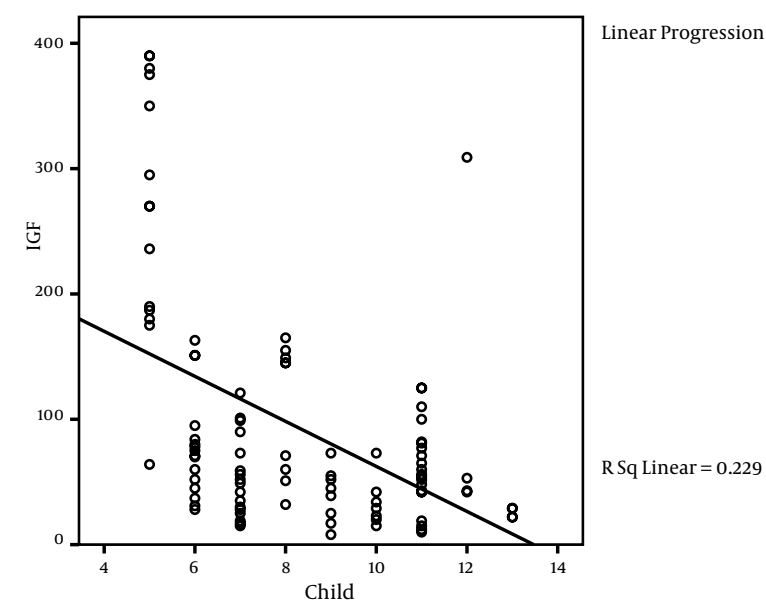

Figure 2. Correlation Between IGF-1 and Child-Pugh Score 


\section{Discussion}

In our study, most of the patients were in the fourth and fifth decades of their lives and the mean age of patients was 44 years. The most common causes of liver cirrhosis in these patients were autoimmune hepatitis, Hepatitis B and Hepatitis $C$. These findings can suggest an increased prevalence of aforementioned diseases in the population or an increase in tendency of these diseases to progress towards liver cirrhosis. The relevant findings along with the laboratory investigations of patients is suspicious for pathologic changes in liver function as is expected in liver cirrhosis in a manner that blood bilirubin would be increased, while serum albumin and platelet count would be decreased. Serum creatinine in these patients was within the normal range after exclusion of patients with renal failure or Hepatorenal Syndrome. So far as staging of severity of liver disease was considered, our findings showed a uniform distribution of patients in Class A, B and C of Child-Pugh scoring system, however, with respect to MELD staging system, distribution of patients was towards the higher scores mostly. Our findings show that most of patients (nearly 85\%) had abnormal IGF-1 level. Complications of cirrhosis had developed in most of our patients; we detected varices in $66 \%$, ascites in $82 \%$ and splenomegaly in $87 \%$ of patients. In all patients a statistically significant relation among IGF-1 and MELD or IGF-1 and Child-Pugh score was found. An inverse relationship was present in both conditions and showed a significant relation with the severity of disease, which MELD or Child-Pugh scores were increased and IGF-1 was decreased. This relation was observed separately in both men and women and did not seem to have any relation with sex of the patients, however between age of patients and IGF-1 a significant inverse relationship was apparent. With an increase in age of patients with cirrhosis, a decrease in IGF-1 levels was observed. In a similar study performed in year 2004, 44 patients with advanced viral cirrhosis were divided into three groups according to Child's scoring and compared with 35 healthy controls. IGF-1 significantly decreased with the progression of cirrhosis and IGF-1 less than $30 \mathrm{ng} / \mathrm{ml}$ was associated with a poor prognosis (25). After distinguishing age of patients in our study, in spite of the fact that an acceptable correlation coefficient was present among IGF-1 and MELD and Child-Pugh score; however lacks of statistical significance on many occasions was detected. It can be owing to the low number of patients in each group. As the correlation coefficient is greatly dependent on the sample size, correlations that were not statistically significant should be interpreted cautiously. It is possible that after increasing the sample size in each age group, relation among these indicators in certain age groups would become significant. However, it seems that IGF-1 along with Child-Pugh or MELD indices are more significant in age groups (2060 years) relative to younger age groups. More studies seem to be necessary in this regard. Our study shows that there is no significant relation between IGF-1 and varices which can be due to presence of other concordant conditions leading to varices than liver dysfunction. However, a meaningful relation was found among IGF-1 and ascites and splenomegaly; patients with splenomegaly and ascites formed a greater proportion of patients with abnormal results of IGF-1 test. In a similar study in 2003, 40 patients with advanced viral and alcoholic cirrhosis and primary biliary cirrhosis with variable severity according to Child staging were evaluated in which the level of IGF-1 was inversely related to the degree of splenomegaly and the severity of cirrhosis (24). Similarly, lab indices including albumin, INR, platelets, and to some extent bilirubin showed significant relation with IGF-1, also patients with abnormal results of IGF-1 test had these lab indices within the abnormal range. In a similar study performed in china in 2001, IGF-1 level was evaluated in patients with chronic liver disease and cirrhosis; lowest IGF-1 level was observed in patients with cirrhosis and also showed a relation with serum albumin level, to the extent that a severe decrease in IGF-1 level was seen at albumin level of $<$ $3 \mathrm{~g} / \mathrm{dL}(26)$. The results of our study suggest that IGF-1 can be an index of severity of cirrhosis and also a marker of liver function; thus can be used for determining severity of the disease in patients in which liver biopsy is not possible.

\section{Acknowledgements}

We most thank Dr. Behnam Baghianimoghadam for his consultation in the translation, editing and publication of the manuscript.

\section{Authors' Contribution}

Asghar Khoshnood has collected the data while research concept and design was by Mohsen Nasiri Toosi and Mohammad Jafar Faravash. Supervision on sampling and interpretation of lab data was by Ahmad Abdollahi. Hosein Froutan and Hadi Ghofrani wrote the article. Critical revision of the manuscript was done by Alireza Esteghamati and Mohammad Kalani; Ali Miroliaee and Andrabi Yasir approved the final version of article for submission and publication.

\section{Financial Disclosure}

None declared.

\section{Funding/Support}

None declared.

\section{References}

1. Le Roith D. Seminars in medicine of the Beth Israel Deaconess Medical Center. Insulin-like growth factors. $N$ Engl J Med. 1997;336(9):633-40. 
2. Friedrich N, Alte D, Volzke H, Spilcke-Liss E, Ludemann J, Lerch $\mathrm{MM}$, et al. Reference ranges of serum IGF-1 and IGFBP-3 levels in a general adult population: results of the Study of Health in Pomerania (SHIP). Growth Horm IGF Res. 2008;18(3):228-37.

3. Life JS, Kipgen WW. Guidelines for the Diagnosis and Treatment of Adult Growth Hormone Deficiency. 2011; [updated 21 Nov 2011] Available from: http://www.cenegenicsfoundation.org/pdf_files| Final_Version-Guidelines_hGH_Rx.pdf.

4. Daughaday WH, Rotwein P. Insulin-like growth factors I and II. Peptide, messenger ribonucleic acid and gene structures, serum, and tissue concentrations. Endocr Rev. 1989;10(1):68-91.

5. Baxter RC. The somatomedins: insulin-like growth factors. Adv Clin Chem. 1986;25:49-115.

6. Jones JI, Clemmons DR. Insulin-like growth factors and their binding proteins: biological actions. Endocr Rev. 1995;16(1):3-34.

7. Chen YH, Hung PF, Kao YH. IGF-I downregulates resistin gene expression and protein secretion. Am J Physiol Endocrinol Metab. 2005;288(5):E1019-27.

8. Thoren MC, Wivall-Helleryd IL, Blum WF, Hall KE. Effects of repeated subcutaneous administration of recombinant human insulin-like growth factor I in adults with growth hormone deficiency. EurJ Endocrinol. 1994;131(1):33-40.

9. Assy N, Hochberg Z, Amit T, Shen-Orr Z, Enat R, Baruch Y. Growth hormone-stimulated insulin-like growth factor (IGF) I and IGFbinding protein-3 in liver cirrhosis. J Hepatol. 1997;27(5):796-802.

10. Caufriez A, Reding P, Urbain D, Golstein J, Copinschi G. Insulinlike growth factor I: a good indicator of functional hepatocellular capacity in alcoholic liver cirrhosis. J Endocrinol Invest. 1991;14(4):317-21.

11. Cuneo RC, Hickman PE, Wallace JD, Teh BT, Ward G, Veldhuis JD, et al. Altered endogenous growth hormone secretory kinetics and diurnal GH-binding protein profiles in adults with chronic liver disease. Clin Endocrinol (Oxf). 1995;43(3):265-75.

12. Donaghy A, Ross R, Wicks C, Hughes SC, Holly J, Gimson A, et al. Growth hormone therapy in patients with cirrhosis: a pilot study of efficacy and safety. Gastroenterology. 1997;113(5):1617-22.

13. Scharf JG, Schmitz F, Frystyk J, Skjaerbaek C, Moesus H, Blum WF, et al. Insulin-like growth factor-I serum concentrations and patterns of insulin-like growth factor binding proteins in patients with chronic liver disease. J Hepatol. 1996;25(5):689-99.

14. Shmueli E, Stewart M, Alberti KG, Record CO. Growth hormone, insulin-like growth factor-1 and insulin resistance in cirrhosis.
Hepatology. 1994;19(2):322-8.

15. Chang TC, Lin JJ, Yu SC, Chang TJ. Absence of growth-hormone receptor in hepatocellular carcinoma and cirrhotic liver. Hepatology. 1990;11(1):123-6.

16. Donaghy AJ, Delhanty PJ, Ho KK, Williams R, Baxter RC. Regulation of the growth hormone receptor/binding protein, insulinlike growth factor ternary complex system in human cirrhosis. J Hepatol. 2002;36(6):751-8.

17. Shen XY, Holt RI, Miell JP, Justice S, Portmann B, Postel-Vinay MC, et al. Cirrhotic liver expresses low levels of the full-length and truncated growth hormone receptors. J Clin Endocrinol Metab. 1998;83(7):2532-8.

18. Donaghy A, Ross R, Gimson A, Hughes SC, Holly J, Williams R. Growth hormone, insulinlike growth factor-1, and insulinlike growth factor binding proteins 1 and 3 in chronic liver disease. Hepatology. 1995;21(3):680-8.

19. Petersen KF, Jacob R, West AB, Sherwin RS, Shulman GI. Effects of insulin-like growth factor I on glucose metabolism in rats with liver cirrhosis. Am J Physiol. 1997;273(6 Pt 1):E1189-93.

20. Shmueli E, Miell JP, Stewart M, Alberti KG, Record CO. High insulin-like growth factor binding protein 1 levels in cirrhosis: link with insulin resistance. Hepatology. 1996;24(1):127-33.

21. Pugh RN, Murray-Lyon IM, Dawson JL, Pietroni MC, Williams R. Transection of the oesophagus for bleeding oesophageal varices. BrJ Surg. 1973;60(8):646-9.

22. Kamath PS, Kim WR. The model for end-stage liver disease (MELD). Hepatology. 2007;45(3):797-805.

23. Wiesner R, Edwards E, Freeman R, Harper A, Kim R, Kamath P, et al. Model for end-stage liver disease (MELD) and allocation of donor livers. Gastroenterology. 2003;124(1):91-6.

24. Vyzantiadis T, Theodoridou S, Giouleme O, Harsoulis P, Evgenidis $\mathrm{N}$, Vyzantiadis A. Serum concentrations of insulin-like growth factor-I (IGF-I) in patients with liver cirrhosis. Hepatogastroenterol. 2003;50(51):814-6.

25. Wu YL, Ye J, Zhang S, Zhong J, Xi RP. Clinical significance of serum IGF-I, IGF-II and IGFBP-3 in liver cirrhosis. World J Gastroenterol. 2004;10(18):2740-3.

26. Lou M, Song N, Jin X, Luo SQ, Wang JJ. [Detection of serum free insulin-like growth factor 1 in patients with chronic vira hepatitis]. Zhonghua Shi Yan He Lin Chuang Bing Du Xue Za Zhi. 2001;15(3):291-2. 